\title{
Financial Frictions and the Persistence of History: A Quantitative Exploration
}

\author{
Francisco J. Buera* Yongseok Shin ${ }^{\dagger}$
}

January 2007

\begin{abstract}
The transitional dynamics of the neoclassical growth model is at odds with the growth experiences of many developing economies. For example, consider the post-communist transition of Eastern Europe: Following liberalization, output grew slowly (and even fell), while interest rates and investment rates remained low, contrary to the predictions of the standard growth theory. We incorporate financial frictions and resource misallocation into an otherwise-standard growth model, and account for the observed growth dynamics. We discipline the model by calibrating its stationary equilibrium to the US data on standard macroeconomic aggregates, wealth distribution, and firms' internal v. external financing. Our model economy converges slowly to the steady state, with the interest rate and the investment rate starting low and rising over time. We also obtain a new result on heterogeneity and macroeconomic dynamics: Even though strict approximate aggregation - that relies only on unconditional first moments - does not hold in our economy, the effect of heterogeneity on aggregate dynamics is almost completely captured by conditional first moments.
\end{abstract}

\footnotetext{
*Department of Economics, Northwestern University, 2001 Sheridan Road, Evanston, IL 60208, USA (e-mail: f-buera@northwestern.edu).

${ }^{\dagger}$ Department of Economics, University of Wisconsin, 1180 Observatory Drive, Madison, WI 53706, USA (email: yshin@ssc.wisc.edu).
} 
The transitional dynamics of the neoclassical growth model is characterized by swift convergence to the steady state, staggeringly high real interest rates in the early stages of development, and decreasing investment-to-output ratio over time. However, most economies' growth experiences are at odds with these neoclassical predictions. One such example is the "miracle" economies of East Asia. As Figure 1 illustrates, growth and investment rates were relatively low initially and peaked in the latter stages. More dramatic evidence against the neoclassical growth model can be found in the post-communist transition of the Eastern European economies. The liberalization of these economies was followed by disappointingly low - even negative - growth rates and slowly increasing investment rates (Figure 2). ${ }^{1}$ Even after going through an exhaustive list of modified neoclassical growth models, King and Rebelo (1993) conclude that neoclassical transitional dynamics can only play a minor role in explaining observed growth experiences. This is a fundamental challenge for the neoclassical growth theory.
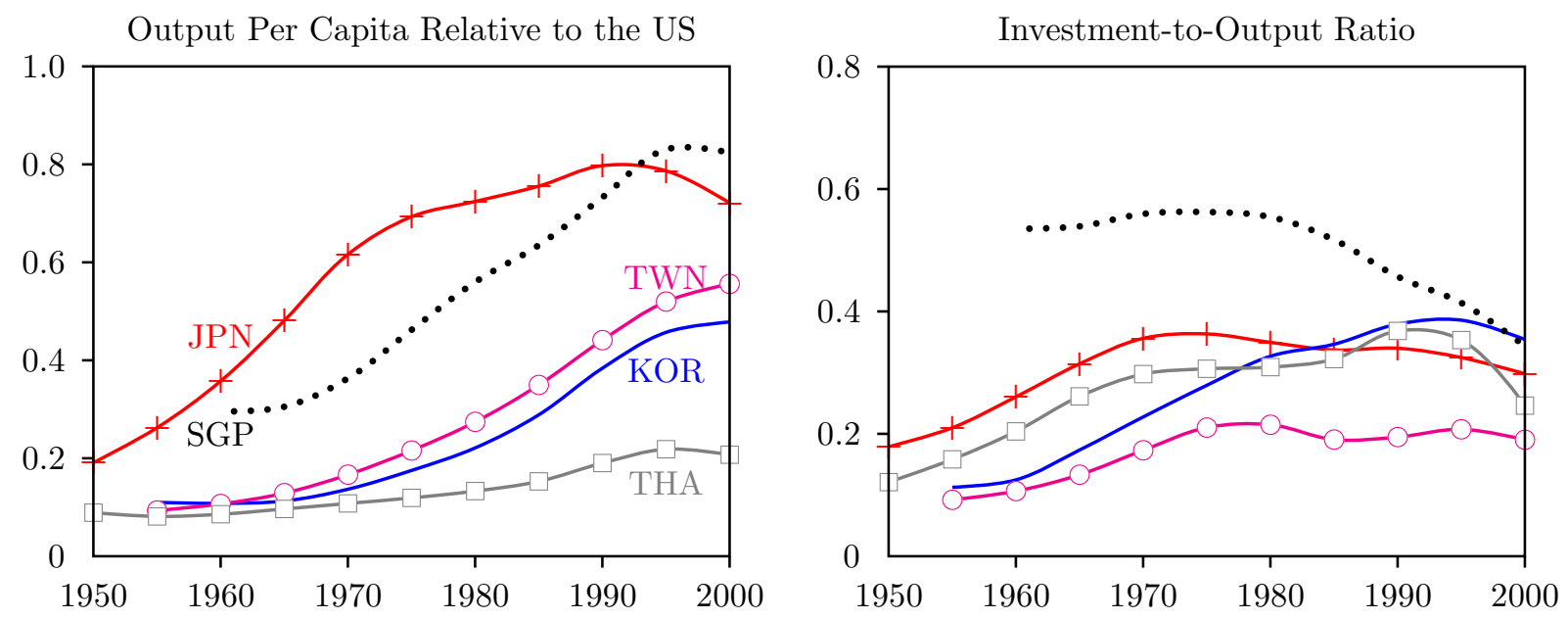

Fig. 1: Real Output and Investment Rate, East Asia

In this paper, we incorporate financial frictions and resource misallocation into the neoclassical growth model, and explore whether the observed transitional dynamics can be accounted for.

Misallocation of resources presupposes differential productivity. Our model features individual-specific technologies. Individuals choose whether to operate an individual-specific technology - become entrepreneurs - or to supply labor for a wage in each period. We assume that different individuals have different entrepreneurial abilities.

\footnotetext{
${ }^{1}$ See Blanchard (1997) and Roland (2000) for an overview of the post-communist transitions.
} 
Output Per Capita, Thousand PPP Dollars

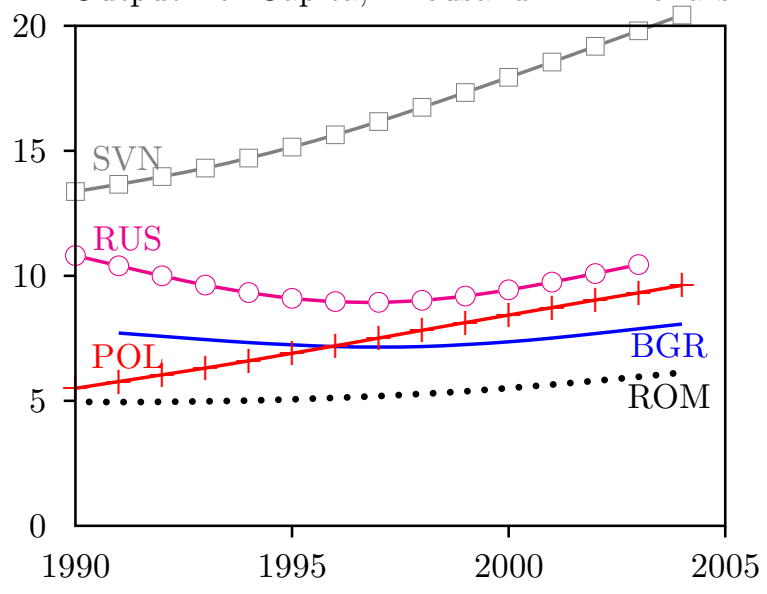

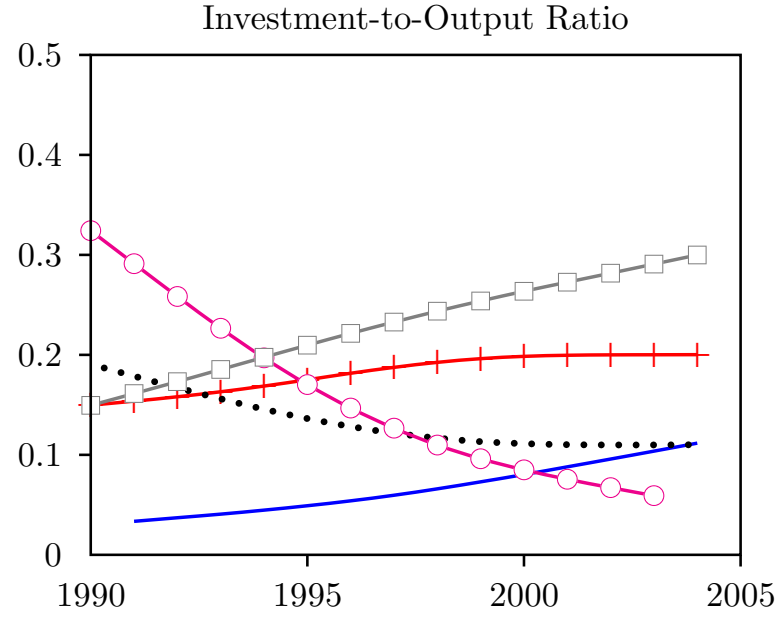

Fig. 2: Real Output and Investment Rate, Post-Communist Transition

Well-functioning financial markets deploy capital to its best use and undo any misallocation. We model financial frictions that inhibit such efficient re-allocation of capital in the economy. In particular, we assume that individuals face collateral constraints - i.e., the maximum capital that an individual can rent is limited by her net worth. With such frictions, a talented entrepreneur who starts poor will have to work for a wage until she has accumulated enough net worth. Even after becoming an entrepreneur, it will take her a while to operate at an efficient scale. With perfect credit markets, she would obtain credit and operate her technology at the maximal-profit scale right away.

Our purpose is to assess the quantitative importance of financial frictions and resource misallocation in understanding transitional dynamics. To this end, we calibrate the model so that its stationary equilibrium resembles the US data in terms of standard macroeconomic aggregates, wealth distribution, and firms' internal v. external financing, among others. We then study the transitional dynamics of the model - starting out with a low level of aggregate capital stock and different degrees of resource misallocation. We also vary the severity of credit constraints and document how financial frictions affect aggregate transition dynamics.

Our first result is that, with financial frictions, the initial distribution of wealth has a significant and enduring impact on the transitional dynamics. Misallocation of initial resources can substantially delay an economy's convergence toward the steady state, unless the economy has perfect credit markets. In our examples with misallocation of the initial capital, the half-life of the aggregate capital stock is typically two or three times that in the perfect-credit economy. 
With severe misallocation, the aggregate capital stock even shrinks initially and rebounds later, generating the output drops observed in some post-communist transitions (e.g., Russia in Figure $2)$.

The behavior of the interest rates and the investment-to-output ratios along the delayed transition is also consistent with the observed growth dynamics. Unlike the neoclassical growth model where the interest rate and the investment rate start out at a very high level and decrease over time, our model generates a wide variety of dynamic paths of these variables. For example, the real interest rate may remain nearly constant along the entire transition, and the investment rate may rise over time in the early stages of economic growth. We conclude that financial frictions and resource misallocation can account for the discrepancy between the observed transitional dynamics and what the neoclassical growth model predicts.

The fact that the wealth distribution has a quantitatively non-trivial impact on aggregate dynamics seems to challenge the "approximate aggregation" results obtained in some macroeconomic models with heterogeneous agents (Krusell and Smith, 1998). Upon further investigation, we show that, although the conventional approximate aggregation fails in our economies, a limited set of cross-sectional moments of the distribution can almost completely characterize the aggregate dynamics of the economy. In particular, the mean wealth level conditional on entrepreneurial ability is found to be a sufficient statistic for the transition dynamics of aggregate variables in our economy. We call this result "conditional approximate aggregation."

Solving for the transitional dynamics of heterogeneous-agent models is a challenging task, and few papers successfully meet the challenge. ${ }^{2}$ To the best of our knowledge, our paper is the first to work out the transition dynamics of a heterogeneous-agent model that embodies the notion of resource misallocation. ${ }^{3}$

Literature Review Christiano (1989) and King and Rebelo (1993) point out that the neoclassical transitional dynamics is inconsistent with the observed growth experiences. They also study whether modified versions of the neoclassical growth model can account for the observed dynamics. The modifications include non-homothetic preferences, adjustment costs and a broader

\footnotetext{
${ }^{2}$ For example, Huggett (1997) maps out the transition dynamics of the economies of Aiyagari (1994) by guessing and iterating on the sequence of interest rates to clear the capital market. The solution algorithm of our model requires guessing and iterating on the sequences of interest rates and of wages to clear both capital and labor markets.

${ }^{3}$ There is a recent literature studying the quantitative implications of models with financial frictions. This literature focuses on models with exogenous or myopic savings (Giné and Townsend, 2004; Jeong and Townsend, 2005a,b) or abstracts from occupational choice (Townsend and Ueda, 2006). These papers do not model the heterogeneity in the returns to capital across entrepreneurs - a dimension that is central to our analysis.
} 
notion of capital, but all of them lead to some counterfactual implications for investment rates, interest rates and/or relative price of installed capital and new investment goods. More recently, Chen et al. (2007) reconcile the neoclassical growth model with the post-war growth experience of Japan. They feed into the neoclassical model the measured realizations of Total Factor Productivity (TFP) as an exogenous process, and show that the resulting dynamics is consistent with the data. In this context, we view our paper as an attempt at providing a theory of TFP along the transitional paths based on the interaction of financial frictions and the initial misallocation of economic resources. ${ }^{4}$

More recently, the disappointing growth experiences of post-communist countries have motivated many researchers to study economic transitions. This literature focuses on the reallocation of factors from state to private enterprises, with a particular emphasis on worker flows and labor market frictions (Blanchard, 1997). Our contention is that capital and entrepreneurial talents were not appropriately aligned during the communist era, and that financial frictions delayed efficient reallocation of capital even after the liberalization. ${ }^{5}$ Atkeson and Kehoe (1997) also attribute the delayed transition of these economies to misallocation of capital. In their model, capital cannot be swiftly reallocated across firms because it takes time for new private firms to accumulate complementary "organizational" capital.

Starting with Banerjee and Newman (1993) and Galor and Zeira (1993), the literature on growth and development points out financial frictions as the central issue on economic development (Banerjee and Duflo, 2005). In these models, borrowing constraints or other financial frictions affect aggregate productivity and the income distribution by restricting agents from profitable occupations that require capital. Stylized examples are constructed where the initial distribution of resources across agents has extremely persistent effects. In fact, in many of these models, the long-run outcomes are fully determined by the initial distribution of wealth. However, given that many special assumptions are imposed on these models for the sake of tractability and that the models deliver mostly qualitative results, it is hard to generalize their implications or assess their quantitative relevance.

Giné and Townsend (2004) and Jeong and Townsend (2005a,b) have pioneered quantitative analysis for this class of models. They estimate and calibrate some models in this literature to the

\footnotetext{
${ }^{4} \mathrm{~A}$ similar argument could be made about the rather limited success of adjustment costs in reconciling the implications of the neoclassical growth model with data. Adjustment costs could be interpreted as a reduced form for financial frictions and misallocation of wealth, which are explicitly modeled in this paper.

${ }^{5}$ In the communist economies, the allocation of capital was as likely to be determined by the distribution of power as by productivity. See Blanchard (1997) and Roland (2000) and references therein. Calvo and Coricelli (1992) argue that credit market frictions inhibited efficient reallocation of capital in Poland after the liberalization.
} 
growth experience of Thailand. The main conclusion of their exercise is that estimated versions of such models do not deliver the interesting aggregate dynamics of growth and inequality predicted by the theoretical literature. Only when they incorporate exogenous variations in financial intermediation over time, can they obtain interesting joint dynamics of growth and inequality. ${ }^{6}$ Arguably, by embracing very special specifications of the theoretical literaturee.g., exogenous savings and very particular forms of heterogeneity, they make it difficult to generalize their quantitative results. In our paper, we develop quantitative methods to study the transitional dynamics of a much broader class of heterogeneous-agent models with financial frictions.

A disparate literature in macroeconomics studies the stationary equilibria and transition dynamics of related models. Aiyagari (1994) shows how introducing idiosyncratic risks leads to a larger aggregate capital stock and to a well-defined invariant distribution of wealth. Huggett (1997) studies the transition dynamics of Aiyagari's economy, but finds only small quantitative differences from those of a representative-agent model. ${ }^{7}$ The case with aggregate shocks is studied by Krusell and Smith (1998). They show that, for the cases with idiosyncratic labor risk, a strong approximate aggregation result holds - that is, the distribution of wealth does not matter for aggregate dynamics in the stochastic stationary equilibrium. ${ }^{8}$

With the issue of heterogeneity and transition dynamics seemingly resolved, some researchers have focused on the difficulty of these incomplete-market models in matching the highly-skewed wealth distribution in the US. More recently, Cagetti and De Nardi (2006) and Quadrini (2000) incorporate financial frictions into models with individual-specific technologies (entrepreneurship), and show that these elements help to explain the empirical wealth distribution. Intuitively, if there are financial frictions, highly-talented entrepreneurs will hold a large ownership stake in their own businesses, which translates into a fat right tail of the wealth distribution. ${ }^{9}$ Given its primary focus on the wealth distribution of the stationary equilibria, this literature

\footnotetext{
${ }^{6}$ See discussions in Townsend (2006), especially Figures 6.1.2.2 and 6.1.2.3.

${ }^{7} \mathrm{He}$ does find qualitative differences between the models. For example, the transitional dynamics of aggregate capital in the heterogeneous-agent model is not necessarily monotonic.

${ }^{8}$ Carroll (2000) argues that, in models with idiosyncratic income shocks, heterogeneity does matter for aggregate dynamics in a more subtle way. If one constructs a representative-agent economy that closely mirrors a given heterogeneous-agent economy, the resulting representative agent could look very different from any of the original heterogeneous agents and also from the typical calibration of representative agents used in macroeconomics.

${ }^{9}$ Entrepreneurship has implications for the level of aggregate capital stock as well. In models with idiosyncratic risks on the return to the individual-specific technologies, there are two opposing forces. The precautionary saving motive will push up the aggregate capital stock in the stationary equilibrium, while the uncertainty will discourage investment in the risky technology and hence capital accumulation. Angeletos (2007) works out the conditions for either force to prevail.
} 
does not study the effects of financial frictions or entrepreneurship on the aggregate dynamics.

Given the potential for explaining slow convergence with models featuring individual-specific technologies, and the success of these models in accounting for many dimensions of inequality in the data, we find it imperative to bring these literatures together and study the joint dynamics of economic growth and inequality. To our knowledge, we are the first to do so with a quantitative emphasis. We begin our analysis by incorporating financial frictions and entrepreneurship into the typical models with heterogeneous agents used in quantitative macroeconomic analysis.

\section{$1 \quad$ Model}

We study economies with individual-specific technologies and imperfect credit markets. Agents choose either to operate an individual-specific technology - i.e. become entrepreneurs, or to work for a wage. Individuals are heterogeneous with respect to their entrepreneurial ability and their wealth. There is exogenous borrowing constraint that is proportional to an individual's net worth.

Heterogeneity and Demographics Individuals are heterogeneous with respect to their birth date $t$, their initial wealth $a_{t}$ and their entrepreneurial ability $e \in \mathcal{E}=\left\{e_{1}, \ldots, e_{N}\right\}$. An individual's ability does not change over the course of her lifetime. Individuals face a constant probability of death $1-\gamma$ each period, and it is assumed that this mortality risk - the only source of uncertainty in this economy - is i.i.d. across individuals. When an individual dies, she is replaced by an off-spring that inherits her wealth, and partially inherits her entrepreneurial ability. The intergenerational transmission of ability follows a Markov process with transition probability $\mu\left(e^{\prime} \mid e\right)$, where $e^{\prime}$ is the ability of the off-spring and $e$ is that of the parent. We denote by $\mu(e)$ the measure of type- $e$ individuals in the invariant distribution. We denote by $G_{t}(e, a)$ the cumulative density function for the joint distribution of ability and wealth at the beginning of period $t$.

The population size is normalized to one, and there is no population growth.

Preferences We assume that there is no bequest motive. We make this assumption in order to abstract from precautionary savings - therefore, the primary purpose of individuals' savings decision is the financing of individual-specific productive investment. Incorporating altruistic behavior is a straightforward extension. The preferences over consumption sequences $c=\left\{c_{s}\right\}_{s=t}^{\infty}$ 
of an individual born in period $t$ are represented by the following utility function:

$$
U(c)=\sum_{s=t}^{\infty} \hat{\beta}^{s-t} \mathbb{E}_{t} u\left(c_{s}\right) .
$$

With the i.i.d. mortality risk being the only source of uncertainty facing an individual, her preferences can be re-written as:

$$
U(c)=\sum_{s=t}^{\infty} \beta^{s-t} u\left(c_{s}\right),
$$

where $\beta=\hat{\beta} \gamma$-i.e. the effective discount factor is equal to the discount factor times the survival probability.

Technologies In any given period, individuals can choose either to work for a wage or to operate an individual-specific technology. We label the latter option as entrepreneurship. An entrepreneur with talent $e$ who uses $k$ units of capital and hires $l$ units of labor produces according to the following production function: ${ }^{10}$

$$
f(e, k, l)=e^{\nu}\left(k^{\alpha} l^{1-\alpha}\right)^{1-\nu}
$$

where $\nu$ is the share of payment going to the entrepreneur- $-\nu$ is known as the span-ofcontrol parameter (Lucas, 1978). Accordingly, $1-\nu$ represents the share of payment going to the variable factors. Out of this, fraction $\alpha$ goes to capital, and $1-\alpha$ goes to labor.

Credit Markets Individuals have access to lending and borrowing at interest rate $r_{t}$, subject to a quantity constraint. In particular, we exogenously limit borrowing in each period to a constant fraction $\lambda-1 \geq 0$ of an individual's wealth at the beginning of the period. This constraint limits the investment of an entrepreneur to:

$$
k_{t} \leq \lambda a_{t} .
$$

\footnotetext{
${ }^{10}$ We will also consider the case where entrepreneurs have the additional option of operating a more efficient technology with minimum scale of production:

$$
f(e, k, l)=B e^{\nu}\left(\min \{0, k-\underline{k}\}^{\alpha} l^{1-\alpha}\right)^{1-\nu}, B>1 .
$$

Banerjee and Duflo (2005) argue that minimum scale is important for misallocation of capital to explain per-capita income differences across countries, and that it is consistent with micro-evidence on the cross-sectional variation of firms' returns to capital in developing countries. Minimum scale is also considered to be an important feature of technologies associated with the Second Industrial Revolution (Mokyr, 2001). See Mokyr (1990) and especially Braggion (2004) for evidence that financial constraints affected the adoption of technologies associated with the Second Industrial Revolution.
} 
In this context, $\lambda$ measures the degree of credit frictions, with $\lambda=+\infty$ corresponding to perfect credit markets.

We choose this specification of credit frictions as it offers a very parsimonious representation of a general prediction of various models of imperfect credits: the amount of borrowing is limited by the net worth of entrepreneurs. In doing so, we are abstracting from the implications of particular models endogenizing these collateral constraints. As there is no consensus model of the informational or contractual friction leading to imperfect credit, we favor the choice of a simple exogenous collateral constraint and focus on understanding the effect of this on aggregate dynamics. ${ }^{11}$ This parametrization of credit frictions have also proven useful in recent applied work ((Evans and Jovanovic, 1989; Buera, 2006)).

Agents' problem The problem of an agent in period $t$ can be written as:

$$
\begin{aligned}
& \max _{\left\{c_{t}, a_{t+1}\right\}_{s=t}^{\infty}} \sum_{s=t}^{\infty} \beta^{s-t} u\left(c_{s}\right) \\
& \text { s.t. } c_{s}+a_{s+1} \leq \max \left\{w_{s}, \pi\left(a_{s} ; e, w_{s}, r_{s}\right)\right\}+\left(1+r_{s}\right) a_{s}, \forall s \geq t
\end{aligned}
$$

where $e, a_{t}$ and the sequence of wages and interest rates $\left\{w_{s}, r_{s}\right\}_{s=t}^{\infty}$ are given, and $\pi(a ; e, w, r)$ is the profit from operating an individual technology. The indirect profit function is defined as:

$$
\pi(a ; e, w, r)=\max _{l, k \leq \lambda a}\{f(k, l ; e)-w l-(\delta+r) k\} .
$$

The input demand functions are denoted by $l(a ; e, w, r)$ and $k(a ; e, w, r)$.

A type- $e$ individual with current wealth $a$ will choose to be an entrepreneur if profits as an entrepreneur, $\pi(a ; e, w, r)$, exceed income as a wage earner, $w$. This occupational choice can be represented by a simple policy function. Type-e individuals decide to be entrepreneurs if their current wealth $a$ is higher than the threshold wealth $\underline{a}(e)$, where $\underline{a}(e)$ solves:

$$
\pi(\underline{a}(e) ; e, w, r)=w .
$$

For some $e$, there may not exist such an $\underline{a}$. In particular, if $e$ is too low, then $\pi(a ; e, w, r)<w$ for all $a$. In this case, this type of individuals will never become entrepreneurs. Intuitively, individuals of a given ability choose to become entrepreneurs if they are wealthy enough to run their businesses at a profitable scale. Similarly, agents of a given wealth a choose to become entrepreneurs if their ability is high enough.

\footnotetext{
${ }^{11}$ See Albuquerque and Hopenhayn (2004) and Clementi and Hopenhayn (2006) for recent example of papers deriving credit frictions from underlying contractual and informational frictions, and for a discussion of their different implications.
} 
If the wage and the interest rate are constant, $w_{t}=w$ and $r_{t}=r$ for all $t$, as will be the case in the stationary equilibrium of this economy, then the recursive formulation of the sequence problem (1) is given by the following Bellman equation:

$$
\begin{aligned}
& v(a ; e)=\max _{c, a^{\prime}}\left\{u(c)+\beta v\left(a^{\prime} ; e\right)\right\} \\
& \text { s.t. } c+a^{\prime} \leq \max \{w, \pi(a ; e)\}+(1+r) a .
\end{aligned}
$$

Competitive Equilibrium Given $G_{0}(e, a)$, a competitive equilibrium in this economy consists of sequences of joint distribution of ability and wealth $\left\{G_{t}(e, a)\right\}_{t=1}^{\infty}$, allocations $\left\{\left\{c_{s}\left(e, a_{t}\right), a_{s+1}\left(e, a_{t}\right), o_{s}\left(e, a_{t}\right), l_{s}\left(e, a_{t}\right)\right\}_{s=t}^{\infty}\right\}_{t=0}^{\infty}$, and prices $\left\{w_{t}, r_{t}\right\}_{t=0}^{\infty}$ such that:

1. Given $\left\{w_{t}, r_{t}\right\}_{t=0}^{\infty}, e$, and $a_{t},\left\{c_{s}\left(e, a_{t}\right), a_{s+1}\left(e, a_{t}\right), o_{s}\left(e, a_{t}\right), l_{s}\left(e, a_{t}\right)\right\}_{s=t}^{\infty}$ solves the agent's problem in (1) for all $t \geq 0$;

2. The labor and credit markets clear at all $t \geq 0$ :

$$
\sum_{e \in \mathcal{E}}\left[\int_{\underline{a}\left(e, w_{t}, r_{t}\right)}^{\infty} l\left(a ; e, w_{t}, r_{t}\right) G_{t}(e, d a)-G_{t}\left(e, \underline{a}\left(e, w_{t}, r_{t}\right)\right)\right]=0
$$

and

$$
\sum_{e \in \mathcal{E}}\left[\int_{\underline{a}\left(e, w_{t}, r_{t}\right)}^{\infty} k\left(a ; e, w_{t}, r_{t}\right) G_{t}(e, d a)-\int_{0}^{\infty} a G_{t}(e, d a)\right]=0 ;
$$

3. The joint distribution of ability and wealth $\left\{G_{t}(e, a)\right\}_{t=1}^{\infty}$ evolves according to the equilibrium mapping:

$$
\begin{aligned}
G_{t+1}(e, a)=\gamma \int_{u \leq a} & \int_{a^{\prime}(e, v)=u} G_{t}(e, d v) d u \\
& +(1-\gamma) \sum_{e_{-}} \mu\left(e \mid e_{-}\right) \int_{u \leq a} \int_{a^{\prime}\left(e_{-}, v\right)=u} G_{t}(e, d v) d u .
\end{aligned}
$$

Stationary Competitive Equilibrium A stationary competitive equilibrium in this economy consists of an invariant joint distribution of ability and wealth $G_{\infty}(e, a)$, policy functions $c(e, a), a^{\prime}(e, a), o(e, a), l(e, a)$, and prices $w, r$ such that:

1. Given $w$ and $r, c(e, a), a^{\prime}(e, a), o(e, a), l(e, a)$ solve the agent's problem $((2))$; 
2. The labor and credit markets clear:

$$
\sum_{e \in \mathcal{E}}\left[\int_{\underline{a}(e, w, r)}^{\infty} l(a ; e, w, r) G_{\infty}(e, d a)-G_{\infty}(e, \underline{a}(e, w, r))\right]=0
$$

and

$$
\sum_{e \in \mathcal{E}}\left[\int_{\underline{a}(e, w, r)}^{\infty} k(a ; e, w, r) G_{\infty}(e, d a)-\int_{0}^{\infty} a G_{\infty}(e, d a)\right]=0
$$

3. The stationary joint distribution of ability and wealth $G_{\infty}(e, a)$ solves:

$$
\begin{aligned}
G_{\infty}(e, a)=\gamma \int_{u \leq a} \int_{a^{\prime}(e, v)=u} & G_{\infty}(e, d v) d u \\
& +(1-\gamma) \sum_{e_{-}} \mu\left(e \mid e_{-}\right) \int_{u \leq a} \int_{a^{\prime}\left(e_{-}, v\right)=u} G_{\infty}(e, d v) d u .
\end{aligned}
$$

Perfect Credit Benchmark With perfect credit markets this economy is isomorphic to a standard neoclassical growth model with aggregate production function:

$$
F(K)=A(\mu) K^{\alpha(1-\nu)}
$$

where $K$ is the aggregate capital stock and the constant

$$
A(\mu)=\max _{e_{m}, f}\left(f+\sum_{e>e_{m}} \mu(e) e\right)^{\nu}\left(\sum_{e<e_{m}} \mu(e)+\mu\left(e_{m}\right)-f\right)^{(1-\nu)(1-\alpha)},
$$

embodies the effect of the distribution of entrepreneurial ability on aggregate output.

Behind the aggregate production function lie optimal allocations of individuals to occupations - workers and entrepreneurs - and of capital and labor to active entrepreneurs.

\section{Quantitative Exploration}

In this section, we study the quantitative implications of the model for the transitional dynamics. We calibrate the stationary equilibria of the benchmark economy to the US data on standard macroeconomic aggregates, wealth inequality, the persistence of income across generations, and firms' financing. We then study the transitional dynamics of the model starting from a low initial aggregate capital stocks and with various degrees of misallocation of wealth. We also analyze economies with different tightness of the collateral constraints, which represents different stages of financial development in the economies. 


\subsection{Calibration}

We choose a period utility function of the isoelastic form:

$$
u(c)=\frac{c^{1-\sigma}-1}{1-\sigma} .
$$

The process governing the intergenerational transmission of entrepreneurial ability is assumed to follow a finite-space Markov chain. In particular, our Markov chain approximates the following $\operatorname{AR}(1)$ process using the procedure of Tauchen (1986):

$$
\ln e_{j}=\rho \ln e_{j-1}+\varepsilon_{j}, \varepsilon_{j} \sim N\left(\mu_{\varepsilon}, \sigma_{\varepsilon}^{2}\right) .
$$

We choose a grid of 10 ability types.

Now, we need to specify 9 parameters: two technological parameters $\alpha$ and $\nu$; three parameters describing the process for ability $\rho, \mu_{\varepsilon}$ and $\sigma_{\varepsilon}^{2}$; the degree of financial frictions $\lambda$; the subjective discount factor and the reciprocal of the intertemporal elasticity of substitution $\beta$ and $\sigma$; and the survival probability $\gamma$.

We let $\sigma=1.5$ following the standard practice. A period in the model is set to 5 years, and we let $\gamma=0.89375$ so that the average duration of working lives is 45 years. We follow the literature and set a low value for $\nu=0.15$, and then let $\alpha=0.38$ to match an aggregate share of capital of one third. ${ }^{12}$

We are thus left with 5 parameters $\left(\lambda, \hat{\beta}, \rho, \mu_{\varepsilon}, \sigma_{\varepsilon}^{2}\right)$ to be calibrated by matching 5 moments in the data: the fraction of capital that is externally financed; the real interest rate over 5 years; the persistence of income across generations; the fraction of entrepreneurs in the data; and the share of wealth owned by the top 5-percentile in the US. The first column of Table \# shows the value of these moments in the US data.

The fraction of externally-financed capital (0.60) is obtained by dividing the sum of credit market liabilities of households, non-corporate private sector, and the corporate non-financial private sector from the Flow of Funds data by the aggregate capital stock from the NIPA accounts. ${ }^{13}$ As the target interest rate we take a risk-free interest rate of $2 \%$ per year, implying

\footnotetext{
${ }^{12}$ Atkeson et al. (1996), Atkeson and Kehoe (2005), and Amaral and Quintin (2005) use $\nu=0.15$. Cagetti and De Nardi (2006) calibrate their model to a slightly lower value of $\nu=0.1$, while Guner et al. (2006) choose $\nu=0.20$.

${ }^{13}$ This assumes that the corporate sector does not finance any of their investments by issuing equity. An alternative (and extreme) assumption would be to count all of the capital owned by the corporate sector as externally financed, implying an average value for the US of 0.76 . This number provides an overestimate as only $9 \%$ of the average flow of corporate investment is externally financed. To be conservative, we choose to match a low value. If were to target a larger value of the share of externally financed capital, we would end up calibrating a larger value for $\lambda$ and a relatively larger dispersion of ability when jointly matching wealth inequality. This would make the effects missallocation in economies with worst credit markets to be larger.
} 


\begin{tabular}{lccc}
\hline & US Data & Model & Calibrated Parameters \\
\hline $\begin{array}{l}\text { Capital externally } \\
\text { financed }\end{array}$ & 0.60 & 0.57 & $\lambda=2.5$ \\
$\begin{array}{l}\text { Interest rate } \\
\begin{array}{l}\text { Persistence of income } \\
\text { across generations }\end{array}\end{array}$ & 0.10 & 0.10 & $\hat{\beta}=1.0$ \\
$\begin{array}{l}\text { Entrepreneurs } \\
\begin{array}{l}\text { Wealth held by } \\
\text { top 5\% }\end{array}\end{array}$ & 0.08 & 0.08 & $\mu_{\varepsilon}=-2.4$ \\
\hline
\end{tabular}

Table 1: Moments Used in the Calibration, Calibrated Moments and Parameters

a 10\% rate over a five years period. Solon (1999) surveys estimates for the correlation between a child's and parents' average income in the US and find them to be between 0.3 and 0.5. We choose to match an intermediate correlation of 0.40. In our model, entrepreneurs include managers of privately and publicly owned businesses. We follow (Cagetti and De Nardi, 2006; Castañeda et al., 2003) in identifying (private) entrepreneurs in the data as self-employed business owners, giving a value of $8 \%$. This value is practically identical to fraction of total entrepreneurs in the population (i.e., (top) managers of privately and publicly held firms), as the number of publicly held firms is negligible (around 10000 firms). Finally, we target a share of wealth held by the top $5 \%$ of the wealth distribution of 0.54 (Cagetti and De Nardi, 2006; Castañeda et al., 2003).

The second and third columns of Table 1 show the parameter values and the corresponding moments from the calibrated model. Even though in the model economy all five moments are jointly determined by the five parameters, they are primarily affected by one of them in the order they are introduced in the table. We briefly discuss the identification and the interpretation of some of the non-standard parameter values.

Financial frictions are inferred to be low, $\lambda=2.5$, mainly responding to the large fraction of intermediated capital in the US economy. The model requires a large discount factor, $\beta=1$, to match the interest rate of 10 over a five years periods, a reasonable number for a models that abstracts from voluntary bequests and retirement. A degree of intergenerational correlation of ability of $\rho=0.5$ leads to a model correlation of incomes across generations close to 0.40 , for given values of financial frictions and dispersion of abilities. The other parameters of the 
distribution of talent are primarily determined by the fraction of entrepreneurs and the wealth inequality. ${ }^{14}$

\subsection{Results for the Stationary Equilibrium}
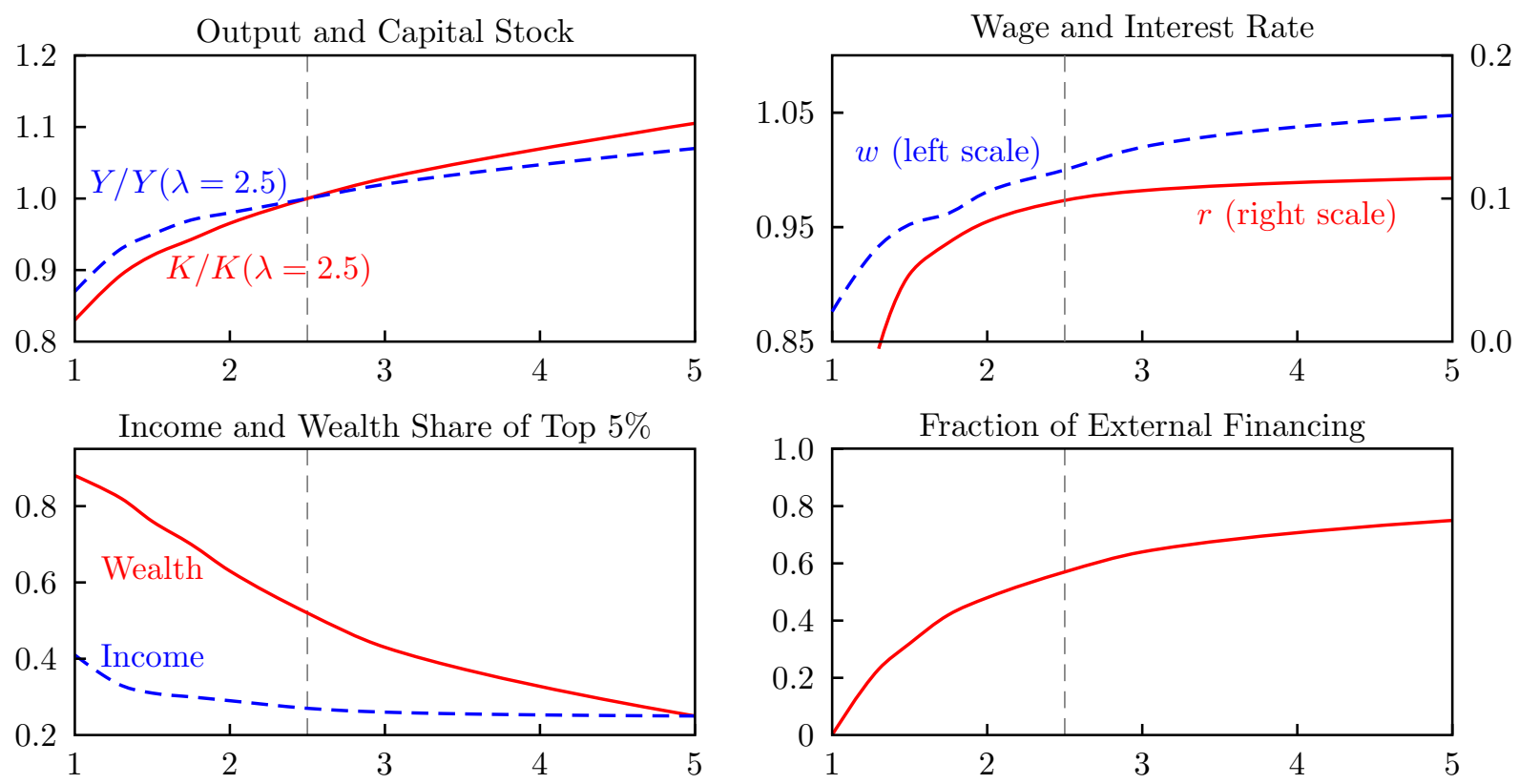

Fig. 3: Effect of Financial Frictions on the Stationary Equilibrium

It is instructive to study the role of financial frictions in the stationary equilibrium. In Figure 3, we consider how allocations and prices respond to changes in the amount of financial intermediation as measure by collateral constraint parameter $\lambda$. Financial frictions have a small effect on aggregate output and capital stock, equilibrium wage, and income inequality as measured by the share of aggregate income held by the top 5-percentile. Varying the collateral constraints has an obviously large effect on the fraction of capital that is intermediated, on the equilibrium interest rate, and measures of wealth inequality.

The top, rightmost panel show the effect of relaxing the collateral constraints on aggregate output and capital. Both variables are measured relative to the calibrated benchmark $(\lambda=2.5)$. When we completely shut down financial intermediation, output declines by less than $15 \%$. This results are explained by the fact that wealth and ability are highly correlated in the stationary equilibrium as both ability and wealth are persistence across generations, and that talented

\footnotetext{
${ }^{14}$ The support of abilities normalized by the lowest ability type equals: $e^{\nu} / \min (e)^{\nu}=\{1,1.13,1.28,1.45,1.65$, $1.86,2.11,2.39,2.71,3.07\}$.
} 
individuals that start poor quickly accumulate large wealth holdings. ${ }^{15}$

Credit market imperfections have a more significant effect on the equilibrium interest rate, wealth inequality, and obviously the share of aggregate capital that is externally financed. As emphasized by Quadrini (2000) and Cagetti and De Nardi (2006), financial frictions models with entrepreneurship are able to amplify wealth inequality for a given degree of income inequality. ${ }^{16}$
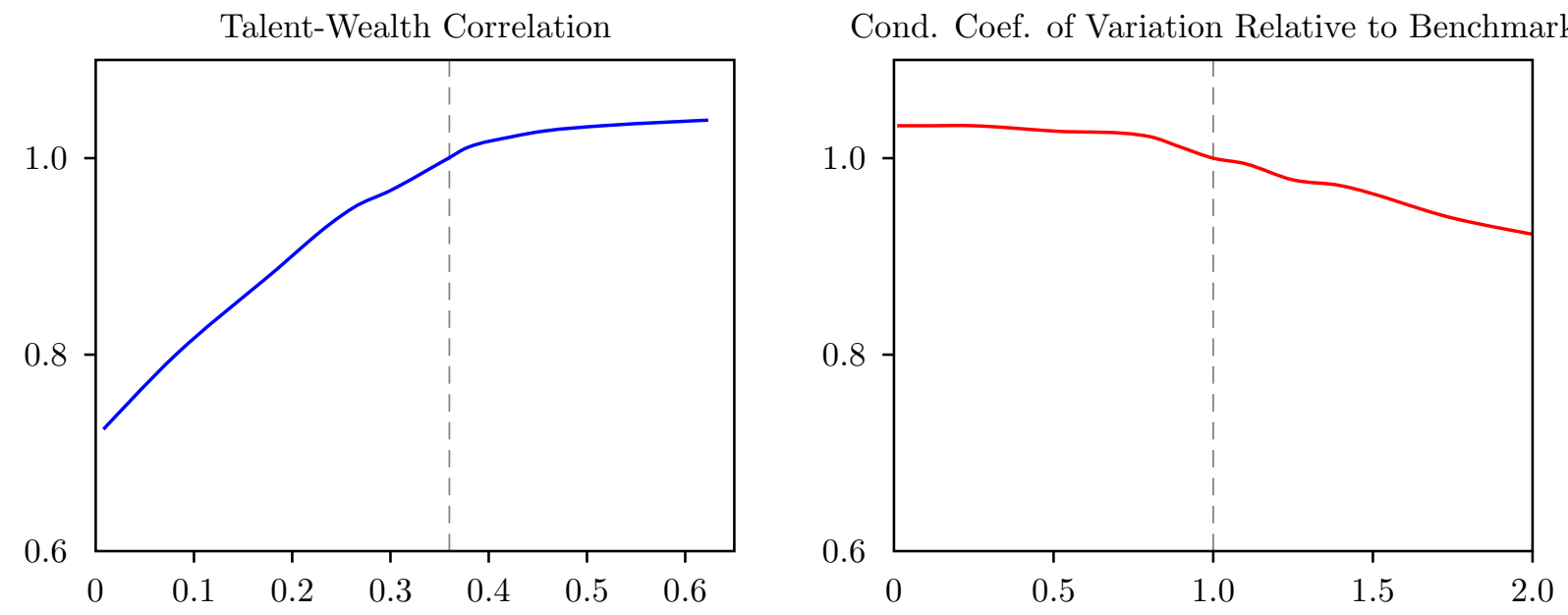

Fig. 4: Aggregate Output as a Function of the Joint Distribution of Wealth and Talent

Before turning to the study of the transitional dynamics of the model, we illustrate how aggregate output varies by changing particular dimensions of inequality starting from the stationary wealth distribution. With financial frictions, aggregate output cannot be described as a simple function of average factors of production - see Equation (3). Instead, aggregate output is a function of the joint distribution of wealth and talent: ${ }^{17}$

$$
Y=\tilde{F}(G(e, a))
$$

Figure 4 illustrates (4) by showing how equilibrium output behaves as a function of the correlation of wealth and talent, and the conditional variance of wealth. The dotted lines show the values associated with the stationary distribution of wealth in the calibrated economy. Interestingly enough, while aggregate output is very sensitive to the correlation of wealth and ability

\footnotetext{
${ }^{15}$ These results are consistent with large welfare costs at the individual level. See Buera (2006).

${ }^{16}$ Notice that like Quadrini (2000), but unlike Cagetti and De Nardi (2006), inequality increases with the tightness of financial frictions.

${ }^{17}$ It is important to emphasize that while (3) is a proper production function, i.e., a description of the maximum output that can be obtained with a given amount of capital and labor, (4) is an equilibrium object describing the aggregate output in an economy with a given distribution of endowments and a given market structure.
} 
(left panel), ${ }^{18}$ it does not responds as much to changes in the conditional variance of wealth (right panel). ${ }^{19}$. Figure 4 is a preview of a result that will be highlighted in the following sections. For the aggregate economy, wealth inequality matters as long as it reflects the allocation of wealth across ability types.

\subsection{Results for the Transitional Dynamics}
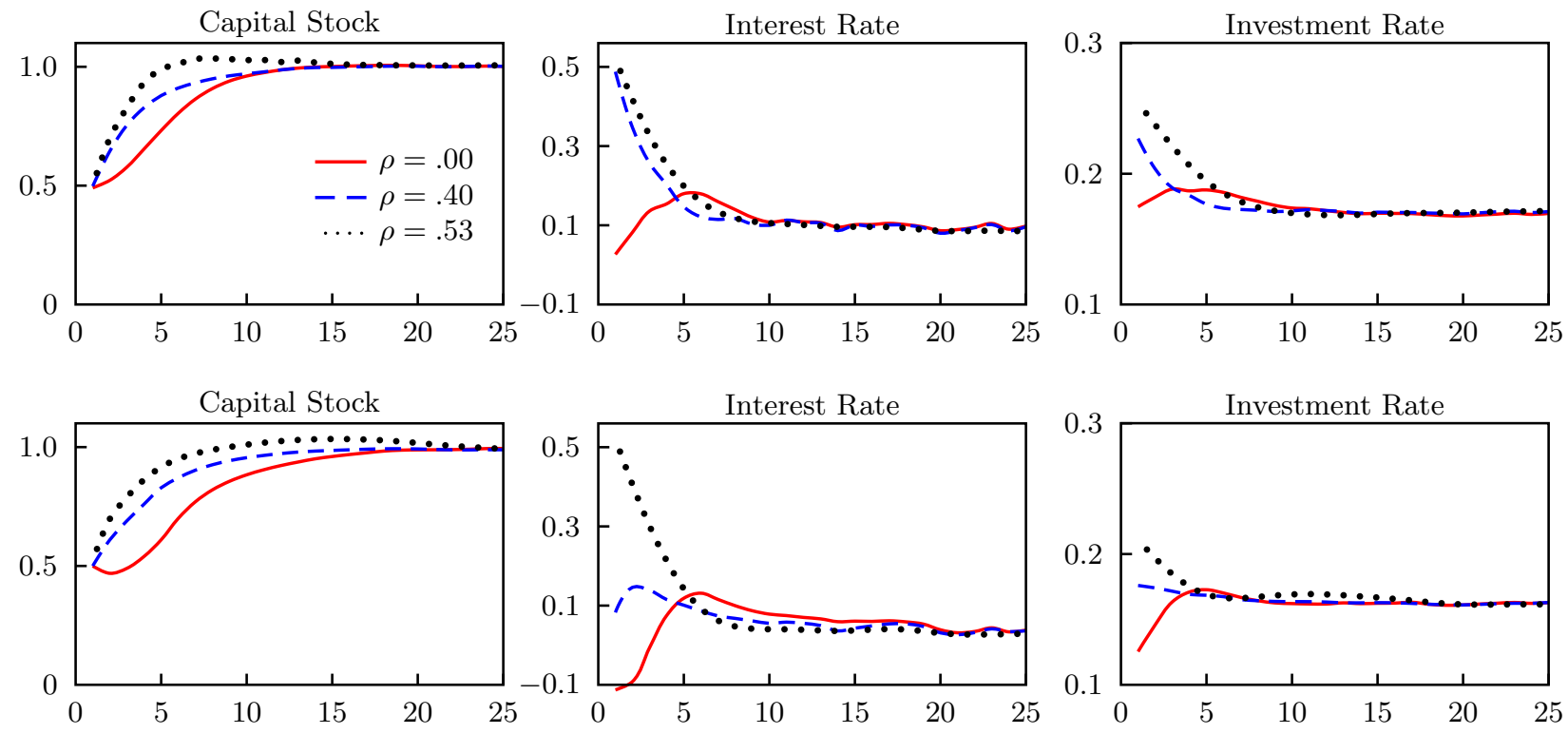

Fig. 5: Transition Dynamics with Financial Frictions (Top Panels: $\lambda=2.5$; Bottom Panels: $\lambda=1.5$ )

In the top panels of Figure 5, we plot the transition paths of aggregate capital, interest rates and investment-to-output ratios for three economies. These economies have financial frictions in the form of $\lambda=2.5$. All three economies share the same technology/preference parameters, and thus have the same stationary equilibrium. These economies start with half the aggregate capital stock of the invariant distribution. They are identical except for the initial distribution of capital. In the first economy (dotted line), the correlation between initial wealth and entrepreneurial ability is 0.53 . This wealth-ability correlation for the second (dashed line)

\footnotetext{
${ }^{18}$ We obtain distributions with lower correlation of wealth and ability by randomly reallocating the wealth and ability for a random subset of agent. As with increase the subset for which this reallocations, the correlation of wealth and ability goes to zero. On the contrary, to obtain distributions with a larger correlation, we mix the original distribution of wealth with a distribution such that each agent is just able to invest the first credit amount of capital.

${ }^{19}$ The right panel is generated by doing a mean preserving spread of each distribution of wealth conditional on ability. The $\mathrm{x}$-axis gives the factor by which each conditional variance is multiplied
} 
and third (solid line) economies is, respectively, 0.4 and 0 . Thus, the third economy has more severe misallocation of initial resources than the other two.

The capital stock figure (top left) reports the aggregate capital for these economies over time, after normalizing by the capital stock of the invariant distribution. ${ }^{20}$

The three economies have markedly different transition paths. In the third (solid line) economy, with the most misallocation of initial resource, only a certain fraction of this "misallocated" capital can be reallocated instantaneously to more productive entrepreneurs, because of the credit constraint. The misallocation can be undone only over time, as the higher-ability types accumulate capital and the lower-ability types retire from entrepreneurial activities. Therefore, for a prolonged period of time, the economy as a whole is less productive than the one without misallocation, and it converges to the steady state at a slower pace.

The effect of misallocation gets more pronounced when the financial frictions are more severe. The lower panels depict the transition dynamics of economies with $\lambda=1.5$.

In the third economy (solid line) where there is more misallocation of initial resources than the other two, the aggregate capital stock drops by about $7 \%$ before it reverts. This economy starts with wealthy lower-ability types who realize that they will not be entrepreneurs for long and that their labor income will rise over time. Thus these low types dissave, and bring the aggregate capital stock down — until the poor higher-ability types' saving catches up. Compared to the second economy, where there is less misallocation, the third one takes twice as long to cover half the distance between the initial aggregate capital stock and the stationary equilibrium capital stock. The effect of the wealthy low types' dissaving can be seen in the investment-tooutput ratio (bottom right). Unlike the other two where the ratio decreases over time, this economy starts with very low investment rate, which is not even monotonic over time.

The main point of King and Rebelo (1993) is that the neoclassical model's prediction on interest rates is inconsistent with data. The bottom center plot shows that, with financial frictions and sufficient misallocation of initial resources, we can generate interest rate paths that start very low and go up gradually over time. In the early stages, the demand for credit is restricted by the borrowing constraint - the poor higher-ability types cannot borrow much because they have negligible net worth. This drives down the market interest rate. As high types become richer, they can borrow more, and the market interest rate gets higher.

The example confirms that, with financial frictions and sufficient misallocation of initial resources, our model can generate slow (even negative) growth, low interest rates and investment

\footnotetext{
${ }^{20}$ The actual computations are done for $T=85$ periods, but we only present more interesting transitional periods. Recall that 1 period in our calibration is equal to 5 calendar years.
} 
rates in the initial stages of economic development. These features are broadly consistent with the transition dynamics of the post-communist economies and that of the "miracle" economies.

\section{$3 \quad$ Heterogeneity and Aggregate Dynamics}

In the previous section, we show that differences in the initial allocation of wealth to individual talent, as measured by changes in the correlation of wealth and ability, has quantitatively important effects on the transitional dynamics. On the other hand, differences on the allocation of wealth within ability types were found to have small effects. In principle, these comparative statics do not exhaust the potentially complex interactions between the wealth distribution (an infinitely dimensional object) and aggregate dynamics. ${ }^{21}$ In this section, we fully characterize which aspects of the wealth distribution are important for explaining the aggregate dynamics of the economy. In particular, we provide an answer to the following question: Which is the minimum set of moments of the wealth distribution across agents that will suffice for a "good" approximation of the law of motion for aggregate variables in the economy?

To be more specific, let $G_{t}(a, e)$ be the joint distribution of wealth and entrepreneurial ability in period $t$, and $m_{t} \in R^{N M}$ be a vector with the first $M$ moments of $G_{t}(a, e)$ conditional on $e \in\left\{e_{1}, \ldots, e_{N}\right\}$. For example, when $M=N=2, e \in\left\{e_{L}, e_{H}\right\}, m_{t}$ has the mean wealth of either entrepreneurial ability type, and standard deviation of wealth for either type. ${ }^{22}$ We are interested in the smallest set of moments $m_{t}$ whose evolution starting from a wide range of initial wealth distributions $G_{0}(a, e)$ can be well approximated by a system of first order difference equations: $m_{t}=H\left(m_{t-1}\right)$, and the history of prices can be well approximate as a function of these moments.

Using the algorithm described in the appendix, we solve for the transitional dynamics of $N$ economies that only differ in their initial distribution of wealth $G_{0}(a, e)$. We index the initial wealth distributions by the first $M^{\prime}$ conditional moments where $M^{\prime} \geq M$, and then form a grid over these $M^{\prime}$ moments. This gives us $N$ histories of length $T$ for the vector of moments $m_{t}$. Note that all the elements of $m_{t}$ are cross-sectional moments. We then find with in a given class of functions, the function $H$ that best fits the evolution of the vector $m_{t}$ for these $N$ histories in the Markovian sense.

We find that for this class of models first and second moments are sufficient state variables

\footnotetext{
${ }^{21}$ In general, the current distribution of wealth might not fully encapsulate the entire history of the economy. See Duffie et al. (1994) and Miao (2006) for a discussion on this topic. Certainly, the algorithm we use to compute the transitional dynamics does not restrict us to recursive competitive equilibria.

${ }^{22}$ Throughout the exercises, we fix the marginal distribution of entrepreneurial talent in the population.
} 
a. Aggregate Capital

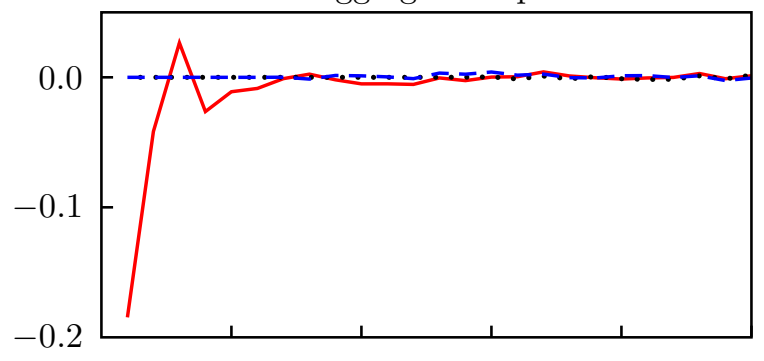

c. Wage

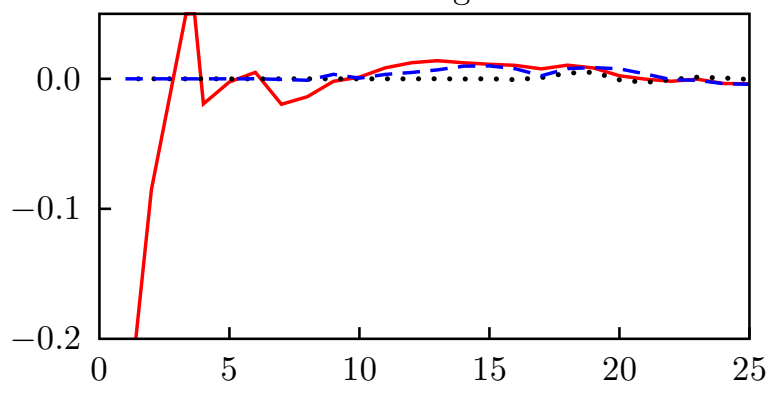

b. Inequality

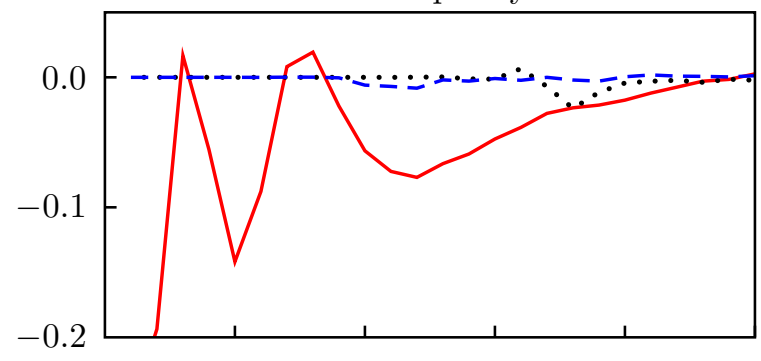

d. Interest Rate

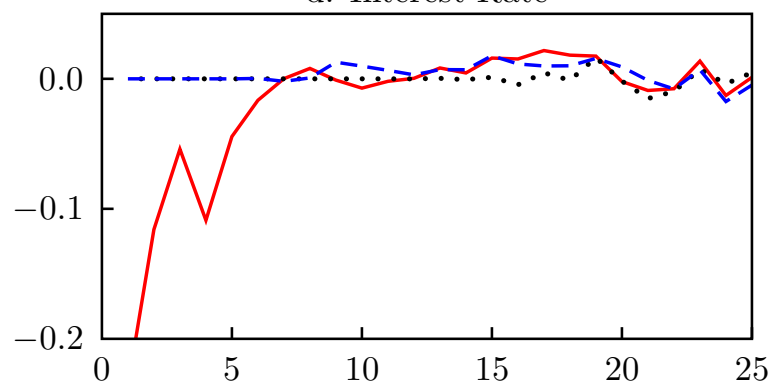

Fig. 6: Approximation Error

for "good" approximation of the law of motion for these moments and prices.

Figure 6 illustrate this point. It describes the approximation error of predicting the evolution of different features of the aggregate state and prices by using various set of moments, $m_{t}$. The solid line corresponds to the case where we only use the average wealth, the dashed line also includes the unconditional variance of wealth and the fraction of wealth held by entrepreneurs, while the dotted line uses only conditional first moments.

In Figure 6.a we show the approximation error of predicting the evolution of aggregate capital for one of the $N$ transitions. ${ }^{23}$ The solid line correspond to the case where the evolution of aggregate capital is modeled solely as a function of aggregate capital. As suggested by the results describe in Section 2.3, measures of the heterogeneity of wealth across agents are important to describe the aggregate dynamics. Moreover, higher order unconditional moments are not informative enough. Intuitively, more unconditional inequality could be associated with more or less misallocation of capital. Information about the heterogeneity conditional of the entrepreneurial talents is needed to predict the evolution of aggregate capital. This is also true for the evolution of inequality, as measure by the unconditional second moments (6.b), wages (6.c), and interest rates (6.d).

\footnotetext{
${ }^{23}$ In particular, we show the approximation error of predicting the evolution of aggregate capital for the economy that start with aggregate capital $K_{0}=K_{s s} / 2$ and wealth is uncorrelated with ability. Similar pictures are obtain for the transitions starting from other $N-1$ initial distribution of wealth.
} 
It turns out that a good approximation only requires a small set of variables providing information about the extent of the misallocation. The dashed line in Figure 6.a shows the approximation error of predicting the evolution of aggregate capital with the unconditional variance of wealth and the fraction of wealth owned by entrepreneurs, who tend to be high ability types. These two additional moments are sufficient to provide a good approximation to the dynamics of aggregate variables.

The unconditional variance captures both the effect of inequality across types and inequality within an ability type, while the correlation of wealth tend to measure inequality between types. It is interesting to explore the extend to which each of these dimension of inequality matters for aggregate dynamics. The dotted line in Figure 6.b answers this question. Mean wealth conditional on the ability types tend to be sufficient statistics to predict the evolution of aggregate capital. Thus, inequality across ability types is the key dimension of heterogeneity for understanding aggregate dynamics.

Figures 6.b, 6.c, and 6.d show the corresponding approximation errors for describing the evolution of inequality, as measured by the unconditional second moments, wages and interest rates.

To take stocks, unlike Krusell and Smith (1998), in our model economy heterogeneity matters for aggregate dynamics. Still, we recovers a partial counterpart of the approximate aggregation results. First and second moments are sufficient state variables for aggregate dynamics. We refer to this as a partial approximate aggregation result.

\section{Conclusions}

In this paper, we incorporate financial frictions and entrepreneurship into an otherwise-standard neoclassical growth model, and show that these features help explain the observed growth experiences of many developing countries. Our model economy converges to the steady state at a much lower speed than what is predicted by the neoclassical model, with the interest rate and the investment rate starting low and rising along the transition path. With sufficient misallocation of initial resources, the model can even generate output drops in the early phases of development.

We view this paper as a first step in building quantitative models to better understand the joint dynamics of growth and inequality. The case of post-communist Eastern Europe is an ideal example for our model, given the rampant resource misallocation during the communist era and the abrupt liberalizations of its economies. For another example, many Latin Amer- 
ican economies' disappointing performance after market-oriented reforms in the 1990's (Cole et al., 2005; Morley et al., 1999; Mukand and Rodrik, 2005) can be partly explained by the slow reallocation of capital toward more efficient technologies that became available - unequal distribution of resources has been a perennial hallmark of Latin America (Deininger and Squire, 1998; Sokoloff and Engerman, 2000).

One commonly-held view on the income differences across countries is that there are barriers to adopting more productive modern technologies in poor countries (Hall and Jones, 1999; Parente and Prescott, 2000). Our model can be applied to study what will happen when such barriers are ratcheted down: The magnitude and the speed of capital reallocation from traditional sectors to modern manufacturing sectors will be determined by the existing resource allocation across sectors, that under the assumption of large barriers to technology adoption is presumably large, and the degree of financial frictions. More generally, our paper provides a framework to study how different economies will evolve differently when economic policies designed to promote growth are implemented. In this context, one may find our work complementary to the literature explaining cross-country income differentials with institutions.

Our work would not be complete without a better understanding of the sources and extent of misallocation in an economy. For addressing this issue, we find the approaches taken in the recent firm-level inquiries by Hsieh and Klenow (2007) useful and promising. Another aspect of our model that deserves a more thorough treatment is the modeling of financial frictions. In future research, we will consider different sources of imperfections in credit markets and various forms of contractual agreements that deal with such problems. 


\section{A Numerical Algorithm}

\section{A.1 Computing the invariant distribution}

We solve for the stationary equilibrium of this economy based on the nested fixed-point algorithm of Aiyagari (1994). The difference is that we have to iterate on both wage $w_{\infty}$ and interest rate $r_{\infty}$ until both labor and capital markets clear in the stationary equilibrium. We start by fixing a $T$, which is the period by which the economy must have reached the steady state. We choose $T$ to be 250 . We numerically verify that increasing $T$ to 300 does not have any effect on the invariant distribution.

1. Guess the interest rate in the invariant distribution, $r_{\infty}^{i}$.

2. Guess the wage in the invariant distribution, $w_{\infty}^{i, j}$.

3. Given the guesses on interest rate and wage, solve the agent's problem in the stationary equilibrium-Problem (2). Given the optimal decision rule of the agents, simulate $N$ individuals for $T$ periods. We set $N=50,000$.

4. Check the labor market clearing condition in period $T$. If there is excess labor demand (supply), choose a new guess at the wage $w_{\infty}^{i, j+1}$ that is greater (smaller) than $w_{\infty}^{i, j}$.

5. Repeat Steps 3-4 until the labor market clears in period $T$.

6. Check the capital market clearing condition in period $T$. If there is excess capital demand (supply), choose a new guess at the interest rate $r_{\infty}^{i+1}$ that is greater (smaller) than $r_{\infty}^{i}$.

7. Repeat Steps 2-6 until the capital market also clears in period $T$.

\section{A.2 Computing the transition dynamics}

To compute the entire transition dynamics, we have to iterate on the wage and interest rate sequences. Taking the wage and interest rate sequences as given, we solve for the individual's problem-Problem (1), and then check whether labor and capital markets clear for all periods. We fix $T$ at 85 . We numerically verify that increasing $T$ to 100 does not have any effect on the transition dynamics. For wage, we iterate on the wage sequence directly. For interest rate, we first globally approximate the time path of interest rates using Chebyshev polynomials of order 4. Once the Chebyshev coefficients converge, we then iterate on the interest rate sequence directly.

1. Put a minimization routine over the 5 coefficients $\left(\theta \in \mathbb{R}^{5}\right)$ on the Chebyshev polynomials of order 4 . Once $\theta$ is chosen, then the Chebyshev polynomials determine the interest rate sequence as a function of $t,\left\{r_{t}^{i}\right\}_{t=0}^{T}$. 
2. Inside the minimization routine, we iterate on the wage sequence. In particular, guess a wage sequence $\left\{w_{t}^{i, j}\right\}_{t=0}^{T}$. Compute the value function of the stationary equilibrium, and let $v_{T}(a ; e)=v(a ; e)$. By backward induction, taking the wage sequence $\left\{w_{t}^{i, j}\right\}_{t=0}^{T}$ and the interest rate sequence $\left\{r_{t}^{i}\right\}_{t=0}^{T}$ as given, compute the value function $v_{t}(a ; e)$ for $t=T-1, \ldots, 0$. Using the agents' optimal decision rule, simulate $N$ individuals for $T$ periods. We again set $N=50,000$. Check whether the labor market clears. Taking the capital stock and occupation choices as given, construct a sequence $\left\{\varpi_{t}^{i, j}\right\}_{t=0}^{T}$ that clears the labor market for each period. Update the wage sequence: $w_{t}^{i, j+1}=\eta_{w} \varpi_{t}^{i, j}+(1-$ $\left.\eta_{w}\right) w_{t}^{i, j}, \forall t$. Iterate on the wage sequence until convergence. Once the wage sequence converges, compute the squared sum of excess capital supply/demand for each period. The minimization routine will search over $\theta$ to minimize this squared sum.

3. Once the minimizing $\hat{\theta}$ is found, use the resulting $\left\{\hat{r}_{t}\right\}_{t=0}^{T}$ as the initial guess and iterate on the interest rate sequence directly, without using the global approximation based on Chebyshev polynomials.

4. Given the interest rate sequence, repeat Step 2. Check for capital market clearing. Taking the capital stock and occupation choices as given, construct a sequence $\left\{\iota_{t}\right\}_{t=0}^{T}$ that clears the labor market for each period. The updated interest rate sequence now will be $\eta_{r} \iota_{t}+$ $\left(1-\eta_{r}\right) r_{t}^{i}$, for all $t$.

5. Repeat Step 4 until the interest rate sequence converges. 


\section{References}

Aiyagari, S. R. (1994): "Uninsured Idiosyncratic Risk and Aggregate Saving," Quarterly Journal of Economics, 109, 659-684.

Albuquerque, R. And H. A. Hopenhayn (2004): "Optimal Lending Contracts and Firm Dynamics," Review of Economic Studies, 71, 285-315.

Amaral, P. And E. Quintin (2005): "Financial Intermediation and Economic Development: A Quantitative Assessment," Manuscript, Federal Reserve Bank of Dallas.

Angeletos, G.-M. (2007): "Uninsured Idiosyncratic Investment Risk and Aggregate Saving," Review of Economic Dynamics, 10, 1-30.

Atkeson, A. And P. J. Kehoe (1997): "Industry Evolution and Transition: A Neoclassical Benchmark," Working paper, National Bureau of Economic Research.

(2005): "Modeling and Measuring Organization Capital," Journal of Political Economy, 113, 1026-1053.

Atkeson, A., A. Khan, And L. Ohanian (1996): "Are Data on Industry Evolution and Gross Job Uurnover Relevant for Macroeconomics?" Carnegie-Rochester Conference Series on Public Policy, 44, 215-250.

Banerjee, A. V. And E. Duflo (2005): "Growth Theory through the Lens of Development Economics," in Handbook of Economic Growth, ed. by P. Aghion and S. N. Durlauf, Amsterdam: Elsevier, vol. 1A, 473-552.

BanerJee, A. V. And A. F. Newman (1993): "Occupational Choice and the Process of Development," Journal of Political Economy, 101, 274-298.

Blanchard, O. J. (1997): The Economics of Post-Communist Transition, Oxford: Clarendon Press.

Braggion, F. (2004): "Credit Market Constraints and Financial Networks in Late Victorian Britain," Manuscript, Tilburg University.

Butra, F. J. (2006): "Persistency of Poverty, Financial Frictions, and Entrepreneurship," Manuscript, Northwestern University. 
Cagetti, M. And M. De Nardi (2006): "Entrepreneurship, Frictions, and Wealth," Journal of Political Economy, 114, 835-870.

Calvo, G. A. and F. Coricelli (1992): "Stabilizing a Previously Centrally Planned Economy: Poland 1990," Economic Policy, 7, 175-226.

Carroll, C. D. (2000): "Requiem for the Representative Consumer? Aggregate Implications of Microeconomic Consumption Behavior," American Economic Review, 90, 110-115.

Castañeda, A., J. Díaz-Giménez, and J.-V. Ríos-Rull (2003): "Accounting for the U.S. Earnings and Wealth Inequality," Journal of Political Economy, 111, 818-856.

Chen, K., A. İmrohoroĞLu, And S. İmrohoroĞLu (2007): "The Japanese Saving Rate," forthcoming, American Economic Review.

Christiano, L. J. (1989): “Understanding Japan's Saving Rate: The Reconstruction Hypothesis," Federal Reserve Bank of Minneapolis Quarterly Review, 13, 10-25.

Clementi, G. L. And H. A. Hopenhayn (2006): "A Theory of Financing Constraints and Firm Dynamics," Quarterly Journal of Economics, 121, 229-265.

Cole, H. L., L. E. Ohanian, A. Riascos, and J. A. Schmitz, Jr. (2005): "Latin America in the Rearview Mirror," Journal of Monetary Economics, 52, 69-107.

Deininger, K. And L. Squire (1998): "New Ways of Looking at Old Issues: Inequality and Growth," Journal of Development Economic, 57, 259-287.

Duffie, D., J. Geanakoplos, A. Mas-Colell, and A. Mclennan (1994): "Stationary Markov Equilibria," Econometrica, 62, 745-781.

Evans, D. S. And B. Jovanovic (1989): "An Estimated Model of Entrepreneurial Choice under Liquidity Constraints," Journal of Political Economy, 97, 808-827.

Galor, O. And J. Zeira (1993): "Income Distribution and Macroeconomics," Review of Economic Studies, 60, 35-52.

Giné, X. And R. M. Townsend (2004): "Evaluation of Financial Liberalization: A General Equilibrium Model with Constrained Occupation Choice," Journal of Development Economics, 74, 269-307. 
Guner, N., V. Gustavo, and X. Yi (2006): "Macroeconomic Implications of Size-Dependent Policies," Manuscript, Pennsylvania State University.

Hall, R. E. And C. I. Jones (1999): "Why Do Some Countries Produce So Much More Output per Worker than Others?" Quarterly Journal of Economics, 114, 83-116.

Hsien, C.-T. And P. Klenow (2007): "Misallocation and Manufacturing TFP in China and India," Manuscript, University of California at Berkeley.

Huggett, M. (1997): "The One-Sector Growth Model with Idiosyncratic Shocks: Steady States and Dynamics," Journal of Monetary Economics, 39, 385-403.

Jeong, H. And R. M. Townsend (2005a): "Growth and Inequality: Model Evaluation Based on an Estimation-Calibration Strategy," Manuscript, University of Southern California.

- (2005b): "Sources of TFP Growth: Occupational Choice and Financial Deepening," Manuscript, University of Southern California.

King, R. G. And S. T. Rebelo (1993): "Transitional Dynamics and Economic Growth in the Neoclassical Model," American Economic Review, 83, 908-931.

Krusell, P. And A. A. Smith, JR. (1998): "Income and Wealth Heterogeneity in the Macroeconomy," Journal of Political Economy, 106, 867-896.

LuCAS, JR., R. E. (1978): "On the Size Distribution of Business Firms," Bell Journal of Economics, 9, 508-523.

Mino, J. (2006): "Competitive Equilibria of Economies with a Continuum of Consumers and Aggregate Shocks," Journal of Economic Theory, 128, 274-298.

Mokyr, J. (1990): The Lever of Riches: Technological Creativity and Economic Progress, New York and London: Oxford University Press.

- (2001): "The Rise and Fall of the Factory System: Technology, firms, and households since the Industrial Revolution," Carnegie-Rochester Conference Series on Public Policy, 55, $1-45$.

Morley, S. A., R. Machado, and S. Pettinato (1999): "Indexes of Structural Reform in Latin America," Serie de reformas económicas, United Nations Economic Commission for Latin America and the Caribbean, Santiago, Chile. 
Mukand, S. W. And D. Rodrik (2005): "In Search of the Holy Grail: Policy Convergence, Experimentation, and Economic Performance," American Economic Review, 95, 374-383.

Parente, S. L. And E. C. Prescott (2000): Barriers to Riches, Cambridge: Mit Press.

Quadrini, V. (2000): "Entrepreneurship, Saving, and Social Mobility," Review of Economic Dynamics, 3, 1-40.

Roland, G. (2000): Transition and Economics: Politics, Markets, and Firms, Cambridge: MIT Press.

Sokoloff, K. L. And S. L. Engerman (2000): "History Lessons: Institutions, Factors Endowments, and Paths of Development in the New World," Journal of Economic Perspectives, $17,217-232$.

Solon, G. (1999): "Intergenerational Mobility in the Labor market," in Handbook of Labor Economics, ed. by O. C. Ashenfelter and D. Card, Amsterdam: North Holland, vol. 3, 17611800.

Tauchen, G. (1986): "Finite State Markov Chain Approximations to Univariate and Vector Autoregressions," Economics Letters, 20, 177-181.

Townsend, R. M. (2006): "The Thai Economy: Growth, Inequality, Poverty and the Evaluation of Financial Systems," Manuscript, University of Chicago.

Townsend, R. M. And K. Ueda (2006): "Financial Deepening, Inequality, and Growth: A Model-Based Quantitative Evaluation," Review of Economic Studies, 73, 251-293. 